\title{
Randomised controlled trial of breast shells and Hoffman's exercises for inverted and non-protractile nipples
}

\author{
Jo M Alexander, Adrian M Grant, Michael J Campbell
}

\begin{abstract}
Objective-To determine the value of recommending breast shells or Hoffman's exercises, or both, to pregnant women with inverted or non-protractile nipples who intend to breast feed.

Design-Randomised controlled trial with a two treatment by two level factorial design.

Setting-Antenatal clinics in a district general hospital and the community.

Subjects-96 nulliparous women recruited between 25 and 35 completed weeks in a singleton pregnancy with at least one inverted or nonprotractile nipple.
\end{abstract}

Main outcome measures-Anatomical change of nipples, judged blindly before first breast feeding, and success of breast feeding reported by postal questionnaire six weeks postnatally.

Results-Sustained improvement in nipple anatomy was more common in the untreated groups but the differences were not significant $(52 \%(25 / 48)$ shells $v 60 \%(29 / 48)$ no shells; difference $-8 \%(95 \%$ confidence interval $-28 \%$ to $11 \%)$ and $54 \%(26 / 48)$ exercises $v 58 \%(28 / 48)$ no exercises; $-4 \%(-24 \%$ to $16 \%)) .24(50 \%)$ women not recommended shells and $14(29 \%)$ recommended shells $(21 \% ; 40 \%$ to $2 \%)$ were breast feeding six weeks after delivery $(p=0.05)$, reflecting more women recommended shells both deciding to bottle feed before delivery and discontinuing breast feeding. The same number of women in exercise and no exercise groups were successfully breast feeding (0\%; $-20 \%$ to $20 \%) .13 \%$ of women approached about the trial (and planning to breast feed) did not attempt breast feeding.

Conclusions-Recommending nipple preparation with breast shells may reduce the chances of successful breast feeding. While there is no clear evidence that the treatments offered are effective antenatal nipple examination should be abandoned.

\section{Introduction}

About $10 \%$ of pregnant women who intend to breast feed have inverted or non-protractile nipples, ${ }^{1}$ and this may lead to problems establishing and maintaining breast feeding. ${ }^{2}{ }^{3}$ For more than 50 years such women have been advised to prepare their breasts during pregnancy, the most common methods of treatment being breast shells ${ }^{4}$ and Hoffman's exercises.

Breast shells are flat discs with a hemispherical dome that are placed over the nipple under a firm brassière, so that the nipple is pressed into the dome to "gradually stretch and loosen its attachment to the deep structures of the breast." "Hoffman's exercises aim at stretching the nipples by manipulation: "The procedure is one of placing the thumb, or the forefingers, close to the inverted nipple, then pressing into the breast tissue quite firmly and gradually pushing the fingers away from the areola." The procedure is repeated five times in the horizontal plane and then five times in the vertical plane. The exercises are completed by the woman trying to ease the nipple out further by traction at the nipple base.

Despite the common recommendation that pregnant women who have inverted or non-protractile nipples should use breast shells or exercises, or both,,$^{6-10}$ doubts have been raised about their effectiveness, and their use remains controversial. ${ }^{11-13}$ To clarify the effects of such preparation on subsequent breast feeding we conducted a formal randomised controlled trial of the use of antenatal breast preparation for inverted or nonprotractile nipples.

\section{Subjects and methods}

The trial was conducted in Southampton over 23 months in 1987-9. The protocol was approved by the local research ethics committee.

Pregnant women were recruited by midwives working in the antenatal clinic of the district general hospital and in three outlying clinics, and also by five midwives working in the community. Women who intended to breast feed were approached during their antenatal examination and, if they agreed, their nipples were examined. A nipple was considered to be inverted if it was situated on a plane below the areola (that is, it appeared crater like). If the nipple was not inverted the woman was asked to check for non-protractility using a "pinch test," based on the procedure described by Waller. ${ }^{4}$ The woman placed her thumb and forefinger on either side of the nipple just beyond its base, pinching them together to imitate the action of a baby's jaw while feeding. Nipples that did not protrude at least half a centimetre above the areola on pinching were considered non-protractile.

A woman was eligible for the trial if she fulfilled the following criteria: at least one inverted or nonprotractile nipple, nulliparous, singleton pregnancy, intending to breast feed, not planning to offer the baby for adoption, no history of surgery affecting the nipple or areola, not already using breast shells or exercises, and between 25 and 35 completed weeks of pregnancy.

A two treatment by two level factorial design was used. ${ }^{14}$ is After giving their consent women were randomised to one of four possible treatment options: breast shells alone; Hoffman's exercises alone; both breast shells and exercises; and neither breast shells nor Hoffman's exercises. Entry to the trial and allocation of treatment were organised by one of us (JMA) centrally using serially numbered, sealed, opaque envelopes. The randomisation was organised in balanced blocks of 16 to ensure even distribution of the four treatment options. After entry, women were given both oral and written instructions and breast shells were provided according to the allocation.

Information was collected on two occasions after entry to the trial. Firstly, a midwife (who did not know requests for reprints to: Dr Alexander.

BMf 1992;304:1030-2 
the trial allocation) re-examined the woman's nipples after delivery, before the first attempt to breast feed. Secondly, the woman completed a postal questionnaire six weeks after delivery about actual use of breast preparation and about infant feeding.

For the purpose of analysis, women who reported that they had not followed the allocated management were considered to have belonged to the groups to which they had been originally assigned. The principal analyses of outcome examined the "main effects" of the two managements - that is, all those allocated shells were compared with all those who were allocated no shells, and all those allocated exercises were compared with all those allocated not to use exercises. Before analysis a test was carried out to verify that there was no interaction between the two treatments. Statistical tests were two sided and $95 \%$ confidence intervals were calculated. ${ }^{16}$ Continuous variables were analysed by Student's $t$ test when a parametric test was appropriate or by the Mann-Whitney $U$ or Kruskal-Wallis non-parametric tests. Categorical variables were analysed by the $\chi^{2}$ test with Yates's correction in two by two tables. There were no interim analyses.

Before the study no data were available on success rates for breast feeding among women with antenatal nipple inversion or non-protractility. Because of time constraints, recruitment ceased when 96 women had joined. A trial of this size had $50 \%$ power to identify an increase of $20 \%(p<0.05)$ due to one or other of the policies.

\section{Results}

Of the 1926 nulliparous women who were screened for inversion or non-protractility, 130 were judged eligible to participate. Two women were not approached because they were not identified as eligible at the appropriate time. Of the 30 women who refused to take part, nine were unwilling to use shells, four refused to consider shells or exercises, six requested shells or exercises, and 11 decided to bottle feed. Two women recruited to the trial were subsequently excluded from the analyses; one (allocated exercises)

TABLE I-Characteristics of pregnant women with inverted or non-protractile nipples allocated to four treatment groups. Values are medians (ranges) unless stated otherwise

\begin{tabular}{|c|c|c|c|c|}
\hline & $\begin{array}{l}\text { Shells } \\
(n=24)\end{array}$ & $\begin{array}{c}\text { Exercises } \\
(n=24)\end{array}$ & $\begin{array}{l}\text { Shells plus } \\
\text { exercises } \\
(n=24)\end{array}$ & $\begin{array}{l}\text { Control } \\
(\mathrm{n}=24)\end{array}$ \\
\hline Maternal age (years) & $24(16-32)$ & $25(17-33)$ & $24(18-38)$ & $25 \cdot 5(17-37)$ \\
\hline \multicolumn{5}{|l|}{ Anatomical state of nipples ${ }^{\star}$ : } \\
\hline No $(\%)$ inverted & $8(33)$ & $8(33)$ & $7(29)$ & $4(17)$ \\
\hline No (\%) non-protractile & $21(88)$ & $19(79)$ & $19(79)$ & $21(88)$ \\
\hline \multicolumn{5}{|l|}{ Interval between recruitment } \\
\hline and delivery (days) & $59 \cdot 5(32-107)$ & $60 \cdot 5(14-112)$ & $65 \cdot 5(3-102)$ & $52 \cdot 5(31-103)$ \\
\hline Gestational age at delivery (weeks) & $40(37-42)$ & $40(33-42)$ & $39 \cdot 5(34-42)$ & $40(34-42)$ \\
\hline Mean (SD) birth weight (g) & $3299(535)$ & $3415(461)$ & $3262(593)$ & $3228(532)$ \\
\hline \multicolumn{5}{|l|}{$\begin{array}{l}\text { Type of delivery (No (\%) of } \\
\text { women): }\end{array}$} \\
\hline Normal vaginal & $18(75)$ & $18(75)$ & $12(50)$ & $15(63)$ \\
\hline Instrumental vaginal & $4(17)$ & $4(17)$ & $7(29)$ & $3(13)$ \\
\hline Caesarean & $2(8)$ & $2(8)$ & $5(21)$ & $6(25)$ \\
\hline
\end{tabular}

was found to be ineligible because she had had bilateral nipple surgery and the other (allocated both shells and exercises) was never formally enrolled in the trial because of an administrative error.

Table I describes the characteristics of the final study sample of 96 women and shows the comparability of the four study groups. Overall, 27 women had at least one inverted nipple and 80 at least one non-protractile nipple. There were no clear differences between the groups in gestational age and birth weight.

We obtained a $100 \%$ response rate to the postal questionnaire sent for completion six weeks after delivery. Thirty of the 48 women allocated shells reported using them all or most of the time. The commonest reasons given for not wearing shells were pain or discomfort; shells conspicuous under clothing; embarrassment; sweating, rash, eczema, or soreness; and milk leakage. Thirty six of the 48 women allocated exercises carried them out on all or most occasions; the most common reason for non-compliance was forgetfulness. No women in the control group ever used shells or exercises. Thirty eight $(40 \%)$ women were successfully breast feeding six weeks postnatally.

Table II summarises the effects of breast preparation. Sustained improvement in nipple anatomy was more common in the untreated groups with respect to both shells and exercises, but neither difference was significant. Ten $(21 \% ; 95 \%$ confidence interval $40 \%$ to $2 \%$ ) fewer women allocated shells were successfully breast feeding six weeks after delivery compared with women not allocated shells $(p=0 \cdot 05)$. This reflected both more women discontinuing breast feeding and more women deciding by the time of delivery to bottle feed. Four of the five women allocated shells who had decided by the time of delivery not to attempt breast feeding mentioned problems with wearing shells as a reason.

Recommending exercises seemed to have no effect on subsequent breast feeding rates. However, the estimate is imprecise and compatible with both a $20 \%$ decrease and a $20 \%$ increase in breast feeding success.

There was some evidence that exercises, when recommended in combination with shells, mitigated the adverse effect of shells when recommended alone; the breast feeding rate was lowest in the group allocated shells only (four, 17\%) and similar in the exercises only (nine, $38 \%$ ) and combined (10, 42\%) groups. Fifteen (63\%) women in the control group were breast feeding.

The women were also asked in the questionnaire if they had experienced nipple bleeding, latching difficulties, or "breast infection needing antibiotics." There were no clear differences between the groups in these respects, although slightly more women allocated breast shells had postnatal breast infections than other women $(14 \%(6 / 43)$ women who had attempted breast feeding in breast shell groups compared with $6 \%(3 / 47)$ in no shell groups).
« Some women fell into both categories.
TABLE II-Effects of recommending breast preparation with shells and Hoffman's exercises on nipple anatomy and breast feeding

\begin{tabular}{|c|c|c|c|c|c|c|}
\hline & \multicolumn{3}{|c|}{ Shells } & \multicolumn{3}{|c|}{ Exercises } \\
\hline & $\begin{array}{l}\text { No }(\%) \text { recommended } \\
\text { shells } \\
(\mathrm{n}=48)\end{array}$ & $\begin{array}{l}\text { No }(\%) \text { not } \\
\text { recommended shells } \\
(n=48)\end{array}$ & $\begin{array}{l}\% \text { Difference } \\
(95 \% \\
\text { confidence } \\
\text { interval })\end{array}$ & $\begin{array}{l}\text { No }(\%) \\
\text { recommended } \\
\text { exercises } \\
(n=48)\end{array}$ & $\begin{array}{l}\text { No }(\%) \\
\text { not recommended } \\
\text { exercises } \\
(n=48)\end{array}$ & $\begin{array}{l}\% \text { Difference } \\
(95 \% \\
\text { confidence } \\
\text { interval })\end{array}$ \\
\hline $\begin{array}{l}\text { Sustained improvement in nipple } \\
\text { anatomy after delivery } \\
\text { Breast feeding } 6 \text { weeks after } \\
\text { delivery: }\end{array}$ & $25(52)$ & $29(60)$ & $-8(-28$ to 11$)$ & $26(54)$ & $28(58)$ & $-4(-24$ to 16$)$ \\
\hline $\begin{array}{l}\text { Successful } \dagger \\
\text { Discontinued } \\
\text { Never started }\end{array}$ & $\begin{array}{r}14(29) \\
29(60) \\
5(10)\end{array}$ & $\begin{array}{l}24(50) \\
23(48) \\
1(2)\end{array}$ & $-21(-40$ to -2$)$ & $\begin{array}{l}19(40) \\
27(56) \\
2(4)\end{array}$ & $\begin{array}{l}19(40) \\
25(52) \\
4(8)\end{array}$ & $0(-20$ to 20$)$ \\
\hline
\end{tabular}

*Not known for one woman in the control group. Sustained improvement defined as at least a unilateral improvement without a balancing regression on the other side.

tIncludes women giving supplementary or complementary bottle feeds. 


\section{Discussion}

Surprisingly little reliable evidence is available on which to assess the value of antenatal preparation with breast shells or Hoffman's exercises despite their frequent use over many years. The strength of our study is that random assignment minimised the risk of biased selection of the groups for comparison.

We found no good evidence that recommending breast shells conveys any benefit in terms of anatomical change or successful breast feeding. Women allocated shells were significantly less likely to be breast feeding six weeks postnatally. This finding was partly explained by more women discontinuing breast feeding and partly by more women deciding by the time of delivery to bottle feed; most of the women in the last group mentioned the shells as a reason. Shells tended to cause pain, discomfort, skin problems, and embarrassment, findings that run counter to previous reports. ${ }^{471718}$ In addition, some women were troubled by colostrum leakage sufficient to interfere with their use of shells. Further evidence of the unpopularity of shells was that they were the most commonly mentioned reason for refusal to join the trial.

Our study also failed to identify any benefit of the policy of recommending Hoffman's exercises, although we recognise that a moderate, but clinically important, increase in the rate of successful breast feeding of up to $20 \%$ cannot be ruled out. Unlike shells, exercises did not seem to cause any problems. It has been suggested that nipple stimulation caused by exercises could cause uterine contractions, ${ }^{919}$ but we found no evidence to support this, particularly in respect of gestational age at delivery (table I).

Nearly 50 years ago it was suggested that "it [is] possible that ... too much stress on preparation of the breasts may alarm and discourage [a woman] to such an extent that she will refuse even to initiate breast feeding." ${ }^{20}$ Our findings lend support to this suggestion. Only women who said that they intended to breast feed had their nipples examined for protractility. Yet 17 of the 128 women (13\%) approached to join the trial because they had inverted or nonprotractile nipples decided before delivery that they would bottle feed ( 11 before entry to the trial and six after joining the trial). This seems particularly unfortunate given the doubts about the link between poor nipple protractility and nipple soreness caused by breast feeding ${ }^{21}$ and also the lack of evidence that treatment is effective.

\section{USE OF SHELLS AND EXERCISES}

The principal limitation of this trial is the sample size. More precise estimates of the effects of breast preparation will come from an ongoing, larger multicentre trial. ${ }^{22}$ Pending the results of that important study we can see no basis for recommending the use of breast shells other than in the context of such trials; the balance of current evidence is that shells do more harm than good. The value of Hoffman's exercises is a more open question, and although our trial showed no difference between the group allocated exercises and the group allocated no exercises, we cannot rule out a clinically useful effect.

We are concerned by the evidence that the process of screening pregnant women for nipple problems may act as a disincentive to successful breast feeding for women with such problems. As long as there is no clear evidence that the treatments offered to such women are effective we believe that antenatal breast examination to identify non-protractile or inverted nipples should be abandoned. Efforts to help women to breast feed should be concentrated in the puerperium.

We thank the women who took part in this study; the midwives; Fred Anthony, Iain Chalmers, Diana Elbourne, Chloe Fisher, Frank Hytten, Sally Inch, Chris James, Rona McCandlish, Mary Renfrew, Jennifer Sleep, Timothy Wheeler, Sarah Roch, and the late John Dennis; and colleagues in the department of midwifery education, Southampton.

This study was supported by a Royal College of Midwives/ Maws research scholarship and the Iolanthe Trust: Eschmann Brothers and Walsh provided breast shells. The Perinatal Trials Service is supported by grants from Department of Health and Birthright.

1 Alexander JM. The prevalence and management of inverted and nonprotractile nipples in antenatal women who intend to breastfeed $[\mathrm{PhD}$ thesis]. Southampton: University of Southampton, 1991.

2 Hytten FE. Clinical and chemical studies in human lactation. IX. Breast feeding in hospital. BMF 1954;ii: 1447-52.

3 Martin J, White A. Infant feeding 1985. London: HMSO, 1988.

4 Waller $\mathrm{H}$. The early failure of breast-feeding - a clinical study of its causes and their prevention. Arch Dis Child 1946;21:1-12.

5 Hoffman JB. A suggested treatment for inverted nipples. Am 7 Obstet Gynecol 1953;66:346-8.

6 DeLee JB, Greenhill JP. Principles and practice of obstetrics. 9th ed. Philadelphia: WB Saunders, 1947:99.

7 Blaikley J, Clarke S, MacKeith R, Ogden KM. Breast-feeding: factor affecting success - a report of a trial of the Woolwich methods in a group of primiparae. Fournal of Obstetrics and Gynaecology of the British Empire 1953;60:657-69.

8 Gunther M. Infant feeding. Harmondsworth: Penguin Books, 1973:104

9 Lawrence RA. Breastfeeding-a guide for the medical profession. 2nd ed. St Louis: CV Mosby, 1985.

10 Akré J, ed. Infant feeding - the physiological basis. Bull World Health Organ 1990;67(suppl): 19-21, 47, 55 .

11 Hytten FE, Baird D. The development of the nipple in pregnancy. Lancet 1958;i:1201-4.

12 Chalmers I, Enkin M. Miscellaneous interventions in pregnancy: RH immunization; preparation for breast-feeding; external cephalic version. In: Enkin $\mathrm{M}$, Chalmers I, eds. Effectiveness and satisfaction in antenatal care. London: William Heinemann, 1982:209-21.

13 Inch S. Antenatal preparation for breastfeeding. In: Chalmers I, Enkin MW, Keirse MJNC, eds. Effective care in pregnancy and childbirth. Oxford: Oxford University Press, 1989:335-42.

14 Cochran WG, Cox GM. Experimental designs. 2nd ed. New York: Wiley, 1957:148-82.

15 Pocock SJ. Clinical trials-a practical approach. Chichester: Wiley, 1983: 138-41.

16 Gardner MJ, Altman DG. Confidence intervals rather than $p$ values: estimation rather than hypothesis testing. $B M \mathcal{F} 1986 ; 292: 746-50$.

17 Poole K. A matter of confidence. New Generation 1987;6:33-4. 18 Larsen LLV. Prenatal breastfeeding counselling-nipple International foumal of Childbirth Education 1990; February:33-4.

19 Riordan J, ed. A practical guide to breastfeeding. St Louis: CV Mosby, 1983.

20 Ministry of Health. The breast feeding of infants - report of the advisory committee on mothers and children. London: HMSO, 1944. (Public health medical subjects report 91 .

21 L'Esperance CM. Pain or pleasure: the dilemma of early breastfeeding. Birt and the Family fournal 1980;7:21-6.

22 Renfrew MJ, McCandlish $R$. With women: new steps in research in midwifery. In: Roberts H, ed. Women's health matters. London: Routledge, 1992:81-98.

(Accepted 10 February 1992) 